\title{
ICG リンパ管造影を用いた下腹部・陰部リンパ浮腫評価
}

\author{
山本匠成島 三長 光嶋 勲
}

\begin{abstract}
○要約：子宮癌などの骨盤悪性腫瘍治療後には下肢リンパ浮腫をきたすことはよく 知られているが，一部は下腹部・陰部リンパ浮腫による排尿障害・リンパ漏を合併し生活 の質を著しく低下させる．患者が陰部リンパ浮腫を訴えるときにはすでに重症化してい ることがほとんどであり治療は難渋する，重症化前に診断・治療することが望ましく，表 層のリンパ流を詳細に描出できるインドシアニングリーン (ICG)リンパ管造影が有用であ る.下腹部・陰部リンパ浮腫の病態生理的重症度分類, genital dermal backflow (GDB) stage により，陰部リンパ浮腫自覚前に下腹部・院部リンパ浮腫の診断が可能となった。リンパ 循環動態の観点からは，下腹部リンパ浮腫は陰部リンパ浮腫に先行する病態であり，下 腹部リンパ浮腫の診断・治療により除部リンパ浮腫を予防できる可能性がある. ICGリン パ管造影を用いることで骨盤癌治療後リンパ浮腫のより良い管理が期待される.
\end{abstract}

索引用語：リンパ浮腫, ICG リンパ管造影, 㓌部, 下腹部, 早期診断

静脈学 $2014 ； 25(1): 43-47$

\section{はじめに}

子宮癌などの骨盤悪性腫瘍治療後に下肢リンパ 浮腫をきたすことはよく知られており, 圧迫療法 を中心としたリンパ浮腫に対する治療の重要性も 認知されてきている。下肢リンパ浮腫患者の約 1 割が院部リンパ浮腫を合併するとの報告がある が, 陰部リンパ浮腫では難治性のリンパ漏を合併 することもあり治療は難渋することが多い, ${ }^{1,2)}$. 陰 部は下肢に比べると圧迫しにくく，また，リンパ 漏を合併した場合は圧迫療法の施行そのものが極 めて困難となる。われわれは，リンパ管細静脈吻

東京大学医学部形成外科

受付：2013 年 8 月 22 日

第 33 回日本静脈学会総会 (2013 年, 倉敷) 座長推薦演題
合術によりリンパ漏を合併した重症陰部リンパ浮 腫の治療例を報告してきたが，治療効果の観点か らは重症化する前に治療することが望ましい ${ }^{3 \sim 17)}$.

下腹部および陰部は浮腫を自覚しづらく, 䎵骨 上に圧痕を残す浮腫を認める例でも“太っただけ” と自覚している場合がほとんどである。陰部浮腫 を自覚している場合は排尿障害やリンパ漏などを 合併していることが多いため，浮腫自覚前に陰部 リンパ浮腫の診断をすることが肝要である ${ }^{1 \sim 3)}$ ，イ ンドシアニングリーン ( ICG)リンパ管造影は, 被 ばくすることなくリアルタイムに表層リンパ流を 可視化でき, 実用性の高いリンパ動態評価方法で ある ${ }^{18-25)}$. 皮下 $2 \mathrm{~cm}$ までの浅いリンパ流しか可視 化できないが, 容積の小さい陰部リンパ流の評価 ではリンパシンチグラフィより詳細なリンパ流の 評価が可能であり，より有用と考えられる26). 


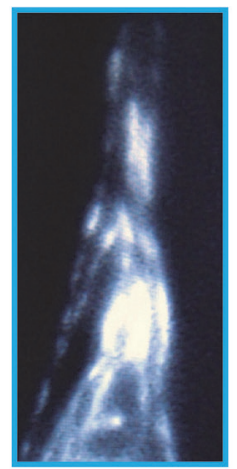

Linear

Normal

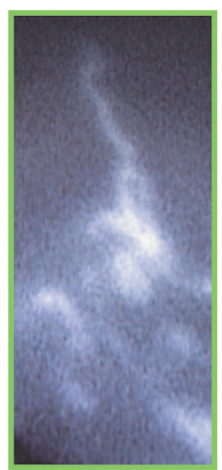

Splash

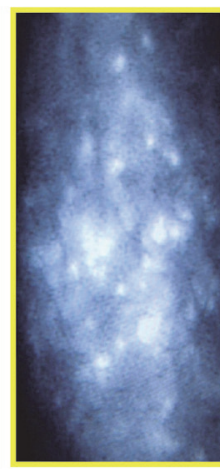

Stardust

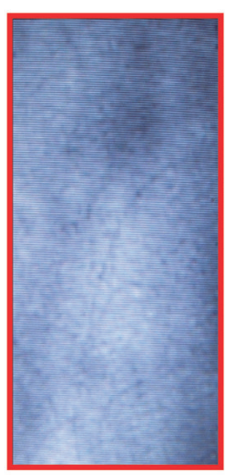

Diffuse

Abnormal (Dermal Backflow)

\section{Progression of Lymphedema}

Fig. 1 Characteristic ICG lymphography findings. With progression of lymphedema, ICG lymphography findings change from linear, to splash, stardust, and finally to diffuse pattern.
閉塞性リンパ浮腫の進行と ICG リンパ管造影 所見

ICG を皮下・皮内注射し近赤外線カメラで観察す ると表層のリンパ流を詳細に観察できる ${ }^{1826)}$ 。健 常例では線状の Linear pattern が観察されるが, 閉 塞性リンパ浮腫例ではリンパの逆流所見である Dermal Backflow (DB) pattern が観察される。閉塞性 リンパ浮腫では, リンパ浮腫の進行に伴い, 閉塞 部位から DB pattern がSplash, Stardust, Diffuseの 順に遠位に進展し, Linear patternがみられなく なっていく(Fig. 1 ${ }^{18-21,26)}$. Splash pattern は蛇行す る線状の所見で, リンパうっ滞により拡張した浅 筋膜より浅い部位のリンパ集合管・前集合管を示し ている. Splashは側副リンパ路であり,これがリ ンパ負荷を代償しきれないと, リンパ管よりリン パ液が間質に漏出し， ICGリンパ管造影で spotsを 呈するようになる。これがStardust patternであ る。リンパ液漏出が高度となると線および点が認 識できない一様に染まった所見 Diffuse pattern を呈 すようになる。

\section{下腹部・陰部の逆行性 ICG リンパ管造影}

下肢 ICG リンパ管造影と同様に, $2.5 \mathrm{mg} / \mathrm{ml}$ の ICG $0.2 \mathrm{ml}$ を第 2 趾間に注射する ${ }^{18,20)}$. 二次性下肢
リンパ浮腫ではすでに浅鼠径リンパ節の変性およ び同部のリンパ逆流を生じているため, 下肢に ICG を注射することで下腹部・院部も逆行性に造影 できる、陰部そのものへの注射は, 疼痛が強く, また, ICG 注射部周囲の造影所見の評価が困難と なるため行わない. ICGの移動が plateauに達した 時点でDB patternの分布から genital DB (GDB) stage を診断する ${ }^{26)}$. 注射後 $12 \sim 18$ 時間が最も鮮 明にSplash, Stardust, Diffuse の違いを可視化でき るが, 患肢の運動を促せば注射後 2 時間以降で診 断可能であり，72 時間後までは GDB stageによる staging が可能である. GDB stage 0 は DBを認めず (Fig. 2A), stage I は鼠径部にSplashのみを認め (Fig. 2B), stage II〜IVでは Stardust を認めるよう になる. Stage II では鼠径部・下腹部に Stardust を 認め(Fig. 2C), stage III では陰部にも Stardust が拡 がり(Fig. 2D), stage IVではStardustを背景に Diffuse を認めるようになる (Fig. 2E). 二次性下肢 リンパ浮腫の女性患者 68 名において逆行性 ICG 陰部リンパ管造影を行い, 全例において GDB stage による分類が可能であり, 副反応・副作用は認めな かった26).

ICG リンパ管造影を用いた陰部リンパ浮腫診療 浮腫が顕在化した時点ではすでにリンパ管変性が 


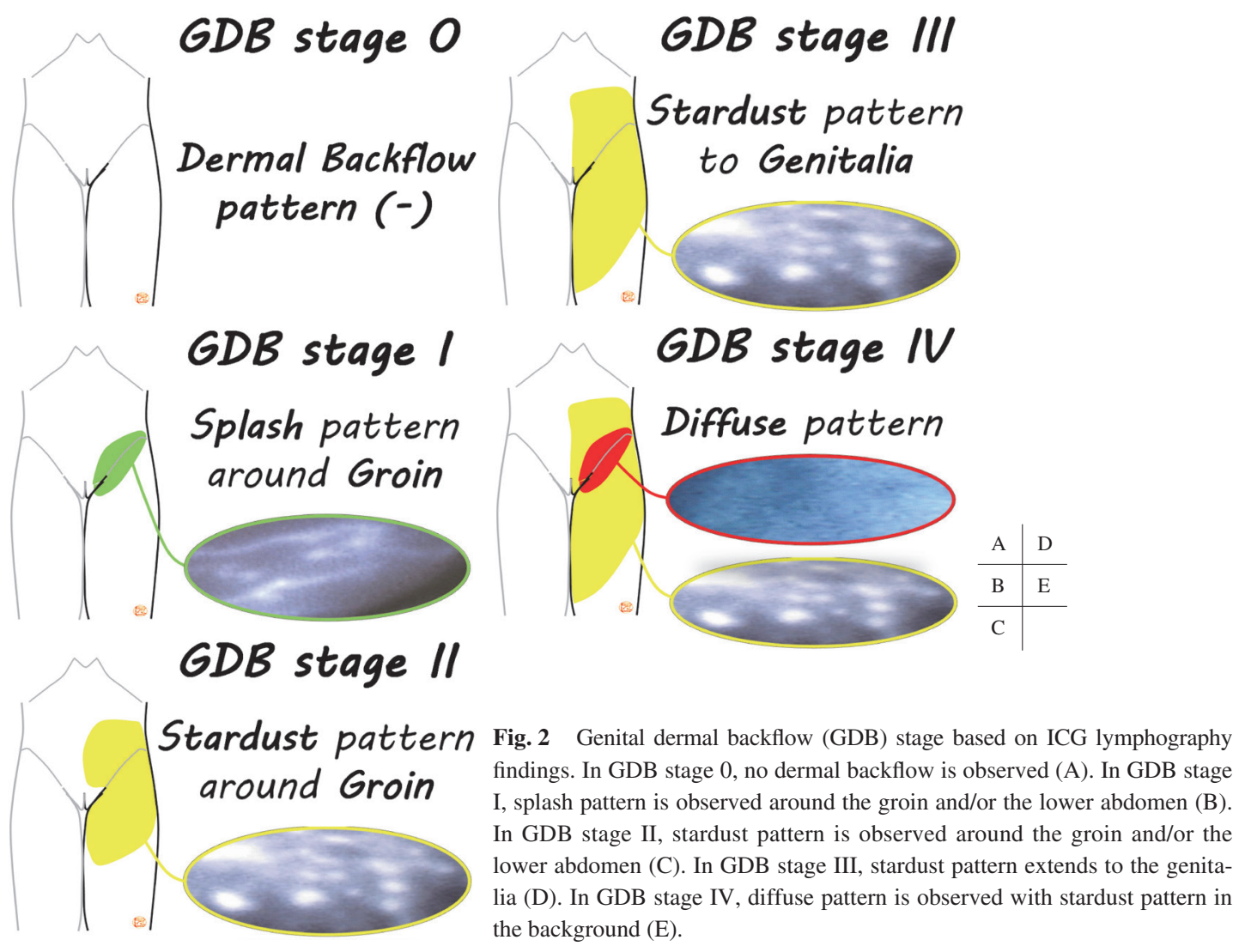

進行しておりリンパ管細静脈吻合術による治療効果 が減弱するため, 浮腫自覚前に異常リンパ循環を検 出しリンパ浮腫を診断する必要がある ${ }^{1 \sim 3,25)}$. 浮腫 の自覚する闇值は個々人によりさまざまであり, 診察上明らかな浮腫を認めていても患者が浮腫を 自覚していないことも少なくない.とくに下腹部・ 陰部では“肥満”と患者・医師双方に誤解されている ことが多い.リンパシンチグラフィがリンパ動態 評価の gold standard とされるが, 容積の小さい陰 部ではリンパ逆流の評価が困難で, ICGリンパ管 造影のように Splash・Stardust・Diffuse といった逆 流の質的評価は不可能である。超音波検査や MRI およびMRリンパ管造影は, 陰部リンパ浮腫の評 価が可能と考えられるが, 今のところ超音波検査 やMRIを用いた重症度評価方法が存在せず，今後 の研究が期待される.

ICG リンパ管造影を用いた GDB stages はリンパ
浮腫の病態生理に基づいた重症度分類であり、リ ンパ浮腫診療に極めて有用と考えられる。つま り，浮腫の自覚の有無にかかわらず, GDB stage 0 は lymphedema (-)で治療適応なし, stage I〜II は下 腹部リンパ浮腫で慎重に経過観察もしくは予防的 治療介入の適応, stage III〜IVは院部リンパ浮腫で あり治療の絶対適応である (Table 1) ${ }^{26,27)}$. リンパ 循環動態の観点からは，下腹部リンパ浮腫は陰部 リンパ浮腫に先行する病態であり (Lower Abdomento-Genitalia sequence; LAG sequence)，下腹部リンパ 浮腫の診断・治療により陰部リンパ浮腫を予防でき る可能性がある26)，われわれはリンパ管細静脈吻 合術による早期リンパ浮腫および不顕性リンパ浮 腫 (subclinical lymphedema)の完治例を報告してき たが ${ }^{17,27)}$, 複合的理学療法などの保存療法との比 較試験はなされておらず, first-line として適切な治 療方法については今後の研究が待たれる。 
Table 1 Genital dermal backflow (GDB) stage and management of lymphedema

\begin{tabular}{lll}
\hline GDB stage & Clinical phase & Management \\
\hline stage 0 & lymphedema $(-)$ & treatment $(-)$ \\
stage I & lower abdominal lymphedema & follow-up or prophylaxis \\
stage II & & \\
stage III & genital lymphedema & aggressive treatments \\
stage IV & & \\
\hline
\end{tabular}

\section{利益相反}

著者全員が利益相反はない.

$$
\text { 文献 }
$$

1) Whitaker $\mathrm{J}$ : Best practice in managing scrotal lymphoedema. Br J Community Nurs 2007; 12: S17,-8, 20-21

2) McDougal WS: Lymphedema of the external genitalia. J Urol 2003; 170: 711-716

3) Yamamoto T, Koshima I, Yoshimatsu H, et al: Simultaneous multi-site lymphaticovenular anastomoses for primary lower extremity and genital lymphoedema complicated with severe lymphorrhea. J Plast Reconstr Aesthet Surg 2011; 64: 812-815

4) Yamamoto $T$, Yoshimatsu $H$, Narushima M, et al: Split intravascular stents for side-to-end lymphaticovenular anastomosis. Ann Plast Surg 2013; 71: 538-540

5) Yamamoto $T$, Narushima M, Yoshimatsu H, et al: Minimally invasive lymphatic supermicrosurgery (MILS): indocyanine green-guided simultaneous multisite lymphaticovenular anastomoses via millimeter skin incisions. Ann Plast Surg 2012 Dec 13 [Epub ahead of print]

6）山本 匠, 成島三長, 光嶋 勲: ICGリンパ管造 影とリンパ管細静脈吻合術によるリンパ浮腫の診 断と治療ならびに神経束反転法による神経再建. 整形・災害外科 2012; 55: 357-364

7）山本 匠, 成島三長, 光嶋 勲：リンパ管細静脈 吻合 (Lymphaticovenular Anastomosis：LVA) 〜超微 小血管吻合によるリンパ浮腫治療〜。血管外科 2011; 30: 45-49

8）山本 匠, 成島三長, 山本奈奈, 他：To Be a Supermicrosurgeon Supermicrosurgery の練習法と 実際～脳神経外科速報 2011; 21: 1114-1120

9）山本 匠, 三原 誠, 光嶋 勲: 下肢リンパ浮腫 に対するリンパ管細静脈吻合 (LVA: lymphaticovenular anastomosis). エキスパート形成再建外科
ひと目でわかる術式選択とテクニック, 初版, 東 京, 2010, 中山書店, pp. 312-325

10）山本 匠, 成島三長, 光嶋 勲：安全で効率的な リンパ管細静脈吻合(LVA)。リンパ学 2010; 33: 67-69

11) Yamamoto $T$, Yoshimatsu $H$, Yamamoto $N$, et al: Sideto-end Lymphaticovenular anastomosis through temporary lymphatic expansion. PLoS ONE 2013; 8: e59523

12) Yamamoto T, Yamamoto N, Azuma S, et al: Nearinfrared illumination system-integrated microscope for supermicrosurgical lymphaticovenular anastomosis. Microsurgery 2013 July 9 [Epub ahead of print]

13) Yamamoto $\mathrm{T}$, Yoshimatsu $\mathrm{H}$, Yamamoto $\mathrm{N}$, et al: Modified lambda-shaped lymphaticovenular anastomosis with supermicrosurgical lymphoplasty technique for a cancer-related lymphedema patient. Microsurgery 2013 Sep 13 [Epub ahead of print]

14) Yamamoto $T$, Yoshimatsu $H$, Narushima $M$, et al: Sequential anastomosis for lymphatic supermicrosurgery: multiple lymphaticovenular anastomoses on one venule. Ann Plast Surg 2012 Dec 13 [Epub ahead of print]

15) Yamamoto $T$, Narushima M, Kikuchi K, et al: Lambdashaped anastomosis with intravascular stenting method for safe and effective lymphaticovenular anastomosis. Plast Reconstr Surg 2011; 127: 1987-1992

16) Yamamoto $T$ : Comment: Selection of anastomosis type for lymphaticovenular anastomosis. J Plast Reconstr Aesthet Surg 2013; 66: 207-208

17) Koshima I, Narushima M, Yamamoto $Y$, et al: Recent advancement on surgical treatments for lymphedema. Ann Vasc Dis 2012; 5: 409-415

18) Yamamoto $T$, Narushima M, Doi K, et al: Characteristic indocyanine green lymphography findings in lower extremity lymphedema: the generation of a novel lymphedema severity staging system using dermal backflow patterns. Plast Reconstr Surg 2011; 127: 1979-1986

19) Yamamoto $T$, Yamamoto N, Doi K, et al: Indocyanine 
green-enhanced lymphography for upper extremity lymphedema: a novel severity staging system using dermal backflow patterns. Plast Reconstr Surg 2011; 128: 941-947

20) Yamamoto $T$, Matsuda N, Doi K, et al: The earliest finding of indocyanine green lymphography in asymptomatic limbs of lower extremity lymphedema patients secondary to cancer treatment: the modified dermal backflow stage and concept of subclinical lymphedema. Plast Reconstr Surg 2011; 128: 314e-321e

21) Yamamoto $T$, Iida $T$, Matsuda $N$, et al: Indocyanine green (ICG)-enhanced lymphography for evaluation of facial lymphoedema. J Plast Reconstr Aesthet Surg 2011; 64: 1541-1544

22) Yamamoto $T$, Narushima M, Yoshimatsu $H$, et al: Indocyanine green velocity: lymph transportation capacity deterioration with progression of lymphedema. Ann Plast Surg 2013; 71: 591-594

23）山本 匠, 成島三長, 光嶋 勲: ICG リンパ管造
影によるリンパ浮腫評価. よくわかるリンパ浮腫 のすべて, 初版, 大阪, 2011, 永井書店, pp. 87-96

24) Yamamoto $T$, Narushima M, Yoshimatsu H, et al: Dynamic indocyanine green lymphography for breast cancer-related arm lymphedema. Ann Plast Surg (in press).

25) Yamamoto $\mathrm{T}$, Yamamoto $\mathrm{N}$, Yoshimatsu H, et al: LEC score: a judgment tool for indication of indocyanine green lymphography. Ann Plast Surg 2013; 70: 227-230

26) Yamamoto $\mathrm{T}$, Yamamoto $\mathrm{N}$, Yoshimatsu H, et al: Indocyanine green lymphography for evaluation of genital lymphedema in secondary lower extremity lymphedema patients. J Vasc Surg: Venous and Lym Dis 2013; 1: 400-405

27) Yamamoto T, Koshima I: Subclinical lymphedema: understanding is the clue to decision making. Plast Reconstr Surg 2013; 172: 472e-473e

\section{Abstract \\ Evaluation of Lower Abdominal and Genital Lymphedema Using ICG Lymphography}

Takumi Yamamoto, Mitsunaga Narushima, and Isao Koshima

Department of Plastic and Reconstructive Surgery, The University of Tokyo

Key words: lymphedema, ICG lymphography, genitalia, lower abdomen, early diagnosis

A part of lower extremity lymphedema patients secondary to pelvic cancer treatments suffer from lower abdominal lymphedema and/or genital lymphedema, which deteriorates patients' quality of life with urination troubles and genital lymphorrhea. Genital lymphedema has already progressed and its treatment is challenging, when a patient complains swelling of her genitalia. It is important to diagnose and commence treatments at an early stage of genital lymphedema. Indocyanine green (ICG) lymphography, which clearly visualizes superficial lymph flows, is considered useful for early diagnosis. Genital dermal backflow (GDB) stage, a pathophysiological severity staging system, allows early diagnosis of lower abdominal and genital lymphedema before symptom manifestation. Lower abdominal lymphedema precedes genital lymphedema from a lymphodynamic point of view, and early diagnosis and intervention to lower abdominal lymphedema may prevent genital lymphedema. ICG lymphography would ameliorate management of lymphedema secondary to pelvic cancer treatments. 